\title{
NAVY RESERVE HUMANITARIAN MISSIONS - OPTOMETRY
}

\author{
CDR Patricia Steiner, OD \\ Navy Reserve Specialty \\ Leader Optometry \\ Psteiner1@att.net \\ doi 10.14434/hindsight.v51i3.31043
}

\begin{abstract}
The author, a U.S. Navy Reserve optometrist for over 30 years, documents some humanitarian missions in which she participated between 2002 and 2018.
\end{abstract}

\section{KEYWORDS}

military optometry, Navy optometry, humanitarian missions

U.S. Navy Reserve medicine has supported humanitarian medical missions providing relief around the globe and within the United States. Originally, military medicine was traveling overseas contributing to the Medical Civic Assistance Programs (MEDCAPS) and Medical Readiness Training Exercises (MEDRETES) to provide medical and dental services, good will, and to receive field training. However, these missions evolved into the Innovative Readiness Training Program (IRT). The IRT program is a training opportunity for the military that is exclusive to the United States providing joint training for deployment readiness in the areas of health care, construction, transportation, and cybersecurity to benefit our American communities. As a Navy Reserve optometrist with over 30 years of service, I have traveled to provide eye care to those in need all over the world doing MEDCAPS, MEDRETES, and IRTs.

My travels have taken me to Thailandriding an elephant through the jungle to flying in a Black Hawk helicopter in temperatures below zero in Alaska, but temperatures above 100 degrees in Haiti. I have seen waterfalls in Guyana and Hawaii. The longest bus ride of my life occurred on the winding road from Lima to Ayacucho, Peru up to an elevation of 10,000 feet. I marched over the Edmund Pettus Bridge in Selma, Alabama. I have seen a dozen eagles in one tree in Alaska and spied a flock of parrots flying overhead in Guyana. I was awed by the northern lights in Anchorage and the city lights of Bangkok. Along with the rib-shaped Barbeque Pork Meals Ready to Eat (MREs) in the field, I have tasted fresh salmon in Alaska, goat in Haiti and chicken foot soup in Thailand. I have found this work the most gratifying and unique experience of my career. Teams of joint optometrists and opticians from reserve and active duty units across the country deployed to worldwide locations, where they would set up their own housing and clinics in locations from school classrooms to field tents. The lines of patients often wrapped around the buildings, the chow ranged from MREs to local made potluck, and if you were lucky there were fans in the sweltering heat, but the joy on your patients' faces could not be beat.My mission experiences include:

\section{Medical Civic Assistance Program (MEDCAP) \\ Cobra Gold Thailand 2002 Medical Civic Assistance Program MEDCAP:}

A team of doctors, dentists, nurses, pharmacists, physical therapists, optometrists and corpsmen traveled to Pataya, Sa Kaeo, and Phitsanulok in Thailand. Our joint team completed 2,025 eye exams in remote villages, referred over 103 patients for cataract surgery, wrote 240 ophthalmic medication prescriptions, while dispensing 1,978 pairs of eyeglasses with over 700 pairs fabricated in the field. Over 2,400 pairs of donated Lions glasses were transported to Thailand for dispensing.

\section{Cobra Gold Thailand 2005 Medical Civic Assistance Program MEDCAP}

A joint multi-national team of 75 medical professionals served 6,217 rural villagers at 11 sites across the Kingdom of Thailand from April 21 to May 5, 2006. This mission traveled to Udon Thani, Chang Mai, Sukothai, and Phuket. Additional sites were added to give support to the areas affected by the 2005 tsunami. The devastation seen in the aftermath of the tsunami and the stories of the survivors were heart breaking. As the Officer in Charge of the MEDCAP, I was responsible for the safety and accountability of the 100-person team including Thai interpreters and Singaporean Medical Team to the 11 sites and 7 different hotels utilizing commercial and military air and ground transportation. The Eye Team on this mission served 3,640 patients, dispensed 3,837 eyeglasses with fabricating 617 pairs in the field, and obtained 6,000 pairs of Lions eyeglasses for the MEDCAPS. In addition, I participated in Cobra Gold Thailand 2006 Medical Civic Assistance Program MEDCAP May 11-28 as the Eye Clinic Coordinator and past Officer in Charge. 


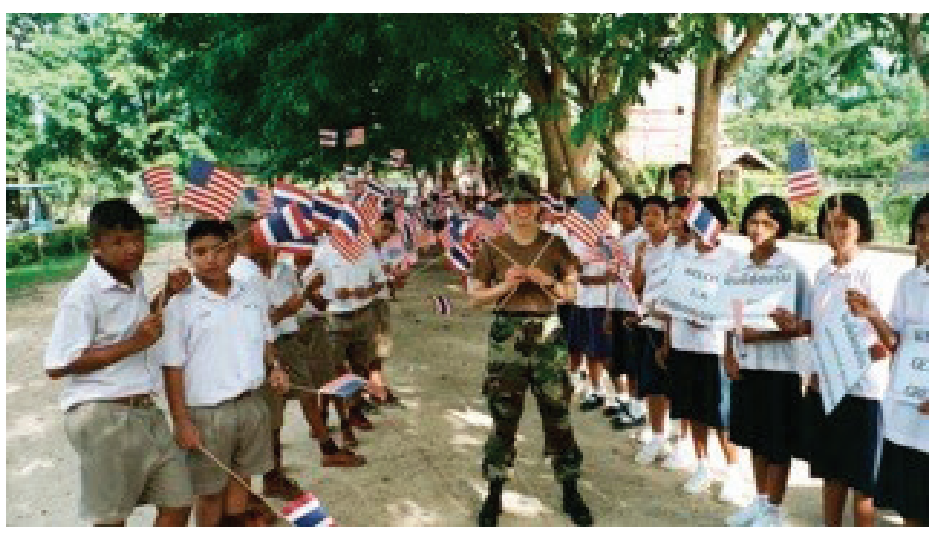

Dr. Steiner with Thai schoolchildren holding Thai and American flags at the Cobra Gold 2002 MEDCAP. Image courtesy the author.

\section{Medical Readiness Training Exercises (MEDRETE)}

\section{New Horizons Medical Readiness Training Exercise MEDRETE, 2008, Ayacucho, Peru}

Working from a Peruvian Army field base under harsh, hot, dusty conditions, a 30-member team provided medical care to over 4,683 patients during the nine-day mission. As an integral component of the optometric department, I provided eye care to over 2,500 patients, dispensing 1,000 pairs of glasses and prescribing over 400 ophthalmic medications. At an elevation over 10,000 feet patients were instructed on Ultraviolet protection as patients were referred for pterygia and cataract surgery.

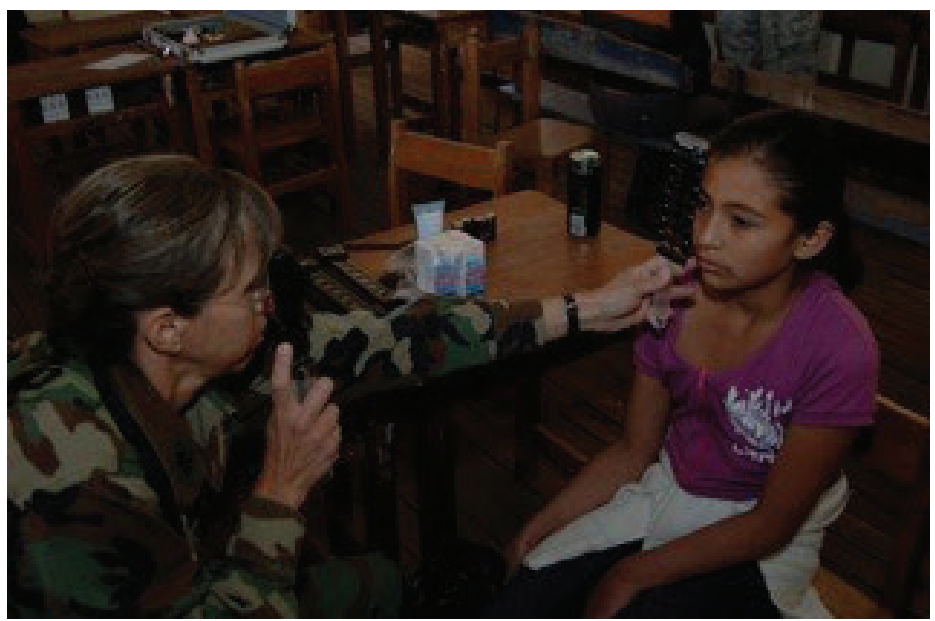

Dr. Steiner seeing an optometry patient during the 2008 New Horizons MEDRETE, Ayacucho, Peru. Image courtesy the author.

\section{New Horizons Medical Readiness Training Exercise MEDRETE, 2009, Linden, Guyana}

The joint mission saw 4,125 patients with 6,205 encounters. The team worked in the almost finished local hospital and stayed at an inn that was once the residence of the local mine owner on the banks of the Demerara River. The optometry team saw 2639 eye patients and dispensed 1969 pairs of eyeglasses. Since supplies were limited and transportation of these supplies was uncertain,
I brought additional ophthalmic medications, over the counter sunglasses and readers to supplement.

\section{Beyond the Horizons Medical Readiness Training Exercise MEDRETE, 2010, Poteau, Haiti}

The Medical Team completed over 6,000 patient encounters. As the sole optometrist at Forward Operating Base KOUT MED, I completed 1,472 eye examinations and dispensed over 1,800 pairs of eyeglasses along with ophthalmic medicines. This mission occurred the summer after the devastating January 2010 earthquake, and the poverty and destruction were overwhelming.

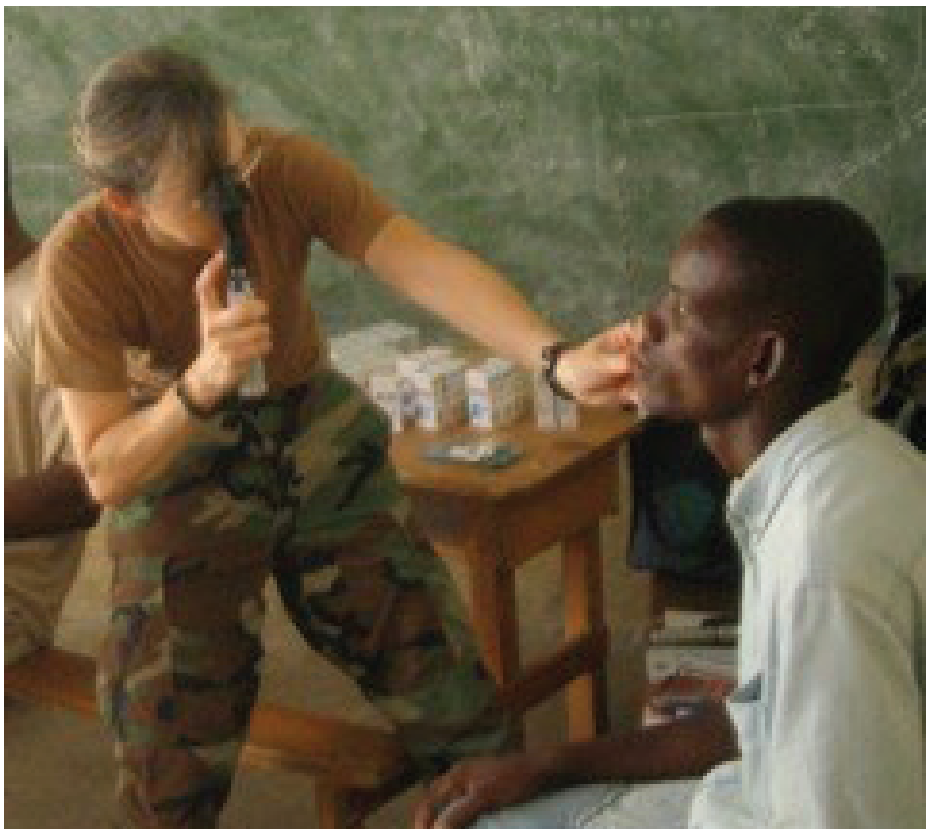

Dr. Steiner examining a patient in a local classroom during Beyond Horizons MEDRETE 2010, Poteau, Haiti. Image courtesy the author.

Innovative Readiness Training (IRT) Program

\section{Arctic Care IRT Mission, Kaltag and Nulato, Alaska, April, 2011}

This joint medical mission spread over isolated villages in central Alaska facilitated the use of helicopters for transport to isolated Native American villages along the Yukon River in below zero temperatures.

Tropic Care IRT Mission, Kauai, Hawaii, February 26 to March 11, 2012

At this joint optometry site, the team completed over 500 eye exams under austere tropical conditions on the south side of the island. The members were housed in the local armory.

\section{Alabama Blackbelt IRT Mission, Hayneville and Selma, Alabama, April 30 to May 11, 2012 and August 6-13, 2012}

Eye exams were provided at the local fire station, while the team stayed at a local church. 


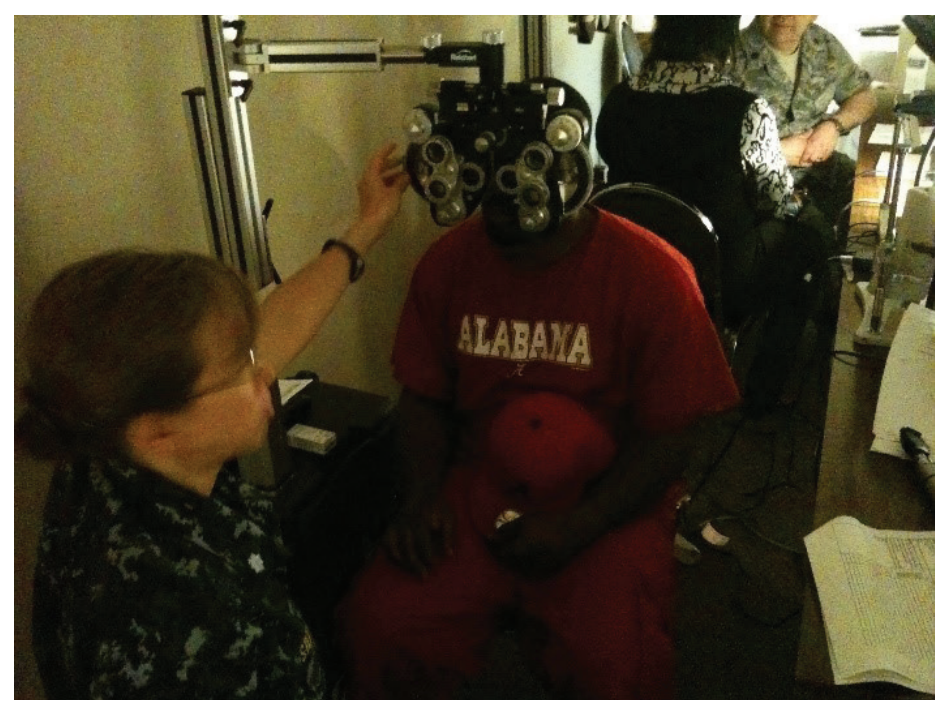

Examining a patient during Alabama Blackbelt IRT in Hayneville, Alabama in 2012. Image courtesy the author.

\section{Tropic Care IRT Mission, Pahala, Hawaii, June, 2013}

Medical mission on the isolated south shore of the Big Island near Kilauea Volcano. The IRT personnel stayed and worked at the local high school.

Hope of Martin IRT Mission, Martin, Tennessee, 2013 took place at the local middle school.

\section{Arctic Care IRT Mission, Kodiak, Alaska, March 29 to April 11, 2014}

As the Optometry Senior Executive, I led five teams of 11 optometrists and technicians at remote austere locations around the island of Kodiak, Alaska, to provide over $\$ 200,000$ of ocular services to residents. Total optometry patients exceeded 700 in this isolated area with over 670 eyeglasses dispensed. I coordinated the logistics of the ophthalmic equipment, medications, eyeglasses, and staffing between the Kodiak Area Native Association (KANA), Navy Ophthalmic Support Training Activity (NOSTRA) and U.S. Coast Guard and Army helicopter assets. I personally examined 177 patients and performed specialized ophthalmic training to five enlisted U.S. Air Force and Navy technicians. At the Kodiak site, the team was berthed at the U.S. Coast Guard Station Armory and worked out of the local public health offices.

\section{Tropic Care IRT Mission Kauai, Hawaii 2014.}

\section{Eastern Alabama Black Belt IRT Mission, Tuskegee, Alabama, June 14-27, 2015}

Optometry served 344 patients out of a local middle school adjacent to the historic Tuskegee University and the airfield commemorating the famous airmen.

\section{Chenango Cares IRT Mission, Norwich, New York, July 11-24, 2015}

Optometry clinic served 334 uninsured residents at the local high school in south central New York state and provided joint ophthalmic training to junior optometrists and enlisted opticians. HINDSIGHT: Journal of Optometry History

\section{Bluegrass IRT Mission, Bardwell, Kentucky, July 16-29, 2016}

As the lead optometrist for the Bluegrass Medical IRT Mission Bardwell site, I administered eye exams and refractions and also dispensed eyeglasses to the predominantly uninsured community of Carlisle County, Kentucky. The clinic staff of three joint service optometrists and two opticians provided 3,139 optometry procedures with a total productivity of $\$ 274,000$.

\section{Tropic Care IRT Mission, Kauai, Hawaii, 2017.}

\section{Tropic Care IRT Mission, Maui, Hawaii, 2018}

There were mission sites over the islands of Molokai, Maui, and Lanai. I was the sole optometrist in Hana Maui serving local residents. Glasses were supplied by NOSTRA. The team was housed in tents adjacent to the Red Sand Beach.

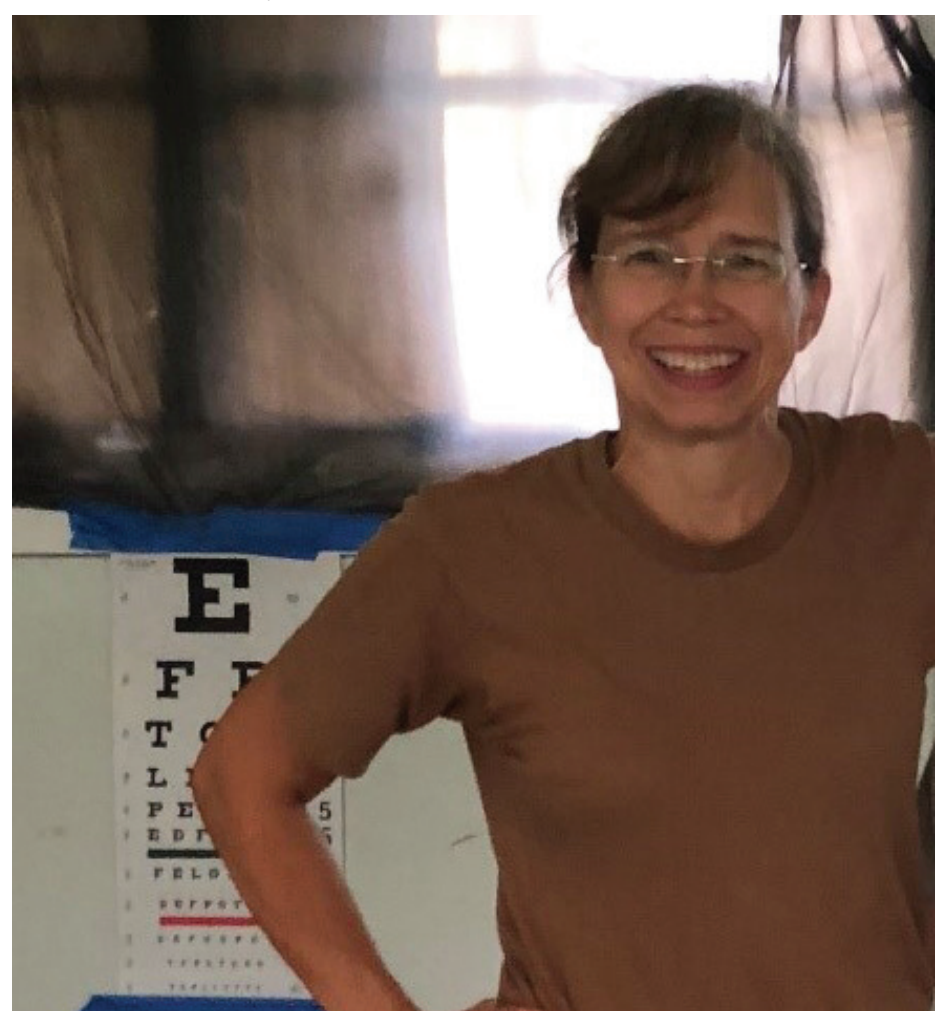

Dr. Steiner in front of a portable acuity chart during Tropic Care IRT, Hana, Maui, 2018. Image courtesy the author.

The Innovative Readiness Training program for 2020 has been modified due to the COVID-19 pandemic, but it is hoped that travel to Georgia for the IRT in August will still be possible. 